\title{
Obesity, Diabetes Mellitus and Vascular Disease: A Complex Relationship with Prostate Cancer
}

\author{
Simona Di Francesco ${ }^{1 *}$, Raffaele L. Tenaglia ${ }^{2}$ \\ ${ }^{1}$ Department of Medicine and Aging, University G. D'Annunzio Chieti-Pescara, Chieti, Italy \\ ${ }^{2}$ Department of Biomedical Sciences, University G. D'Annunzio Chieti-Pescara, Chieti, Italy \\ Email: ${ }^{*}$ docveronica@gmail.com
}

Received 24 February 2014; revised 20 March 2014; accepted 27 March 2014

Copyright (C) 2014 by authors and Scientific Research Publishing Inc.

This work is licensed under the Creative Commons Attribution International License (CC BY). http://creativecommons.org/licenses/by/4.0/

(c) (i) Open Access

\begin{abstract}
Background: Obesity, type II Diabetes mellitus (DMII) and vascular damage could be implicated in prostate cancer (PCa) nevertheless no clear results has been reached. The aim of the research was to investigate the association of these alterations with PCa at initial diagnosis, without the influence of hormone therapy or chemotherapy. Methods: Retrospective analysis of 400 patients undergoing prostate biopsy at our institution between 2005 and 2012 was conducted. We examined associations of obesity, DMII and vascular damage in 200 patients with PCa diagnosis versus 200 age-matched controls. Men with history of hormone therapy or chemotherapy, prostate or bladder surgery were excluded. Results: Obesity was significantly associated (OR $2.10, p<0.05)$ with aggressive PCa (Gleason Score 8 - 10). DMII was significantly associated to aggressive PCa but only in obese cases (OR 4.25). Carotid vascular disease (CVD) and coronary artery disease (CAD) were significantly linked to PCa in all cases versus controls (OR 1.88, $p<0.05)$. Conclusions: In our study, obesity, particularly in combination with DMII, was significantly associated with aggressive PCa. Moreover, a significant relation was found between vascular disease and PCa hormone-naïve at initial diagnosis. The metabolic derangements associated to obesity and DMII may increase oxidative stress and cause a permanent pro-inflammatory state that predisposes to vascular disease and PCa.
\end{abstract}

\section{Keywords}

Prostate Cancer, Obesity, Diabetes Mellitus, Vascular Disease

\footnotetext{
${ }^{*}$ Corresponding author.
} 


\section{Introduction}

Controversy still persists in regarding the influence of obesity and type II Diabetes mellitus (DMII), separately and combined, in Prostate Cancer (PCa) development and aggressiveness [1]-[7].

Recent works have reported that obesity increased or was not associated with the risk of advanced or highgrade tumor. Several studies have reported decreased PCa risk among patients with type DMII and others found either no protective effect or even an elevated risk [7]-[10].

More than $30 \%$ of men with PCa die of cardiovascular disease, which constitutes one of the most common causes of death in this patient population [11]-[13]. Nevertheless, only a few studies have explored the relationship between vascular disease and PCa risk, with inconclusive results [14]-[18].

Indeed, while the relationship between DMII, obesity and PCa has been heavily examined in patients after Hormonal Therapy, the influence of metabolic alterations in PCa hormone-naïve at initial diagnosis has been poorly studied, despite the frequent co-existence of these disorders in PCa [19].

Therefore the aim of the research was to investigate the association of obesity, DMII and vascular damage with PCa hormone-naïve at initial diagnosis.

\section{Methods}

Retrospective analysis of 400 patients undergoing prostate biopsy at our institution between 2005 and 2012 was conducted (Table 1). We examined associations of obesity, DMII and vascular disease (carotid vascular disease and/or symptomatic coronary artery disease) in 200 patients with PCa diagnosis, versus 200 age-matched controls. Men with history of hormone therapy or chemotherapy, prostate or bladder surgery or radiotherapy were excluded. Patients with negative biopsy for PCa, but with atypical small acinar proliferation (ASAP), atypical adenomatous hyperplasia/adenosis, high-grade PIN (HGPIN) were excluded from evaluation.

At baseline, a medical history for Coronary Artery disease (CAD) or Carotid Vascular disease (CVD) for cases and controls was obtained. CVD had evaluated also by B-mode ultrasound-based method. Subjects were considered as normal if no lesion was detected, or having CVD when a plaque, stenosis or occlusion was detected in at least one segment of common, bifurcation or internal carotid artery.

Obesity (BMI $\geq 30$ ), DMII, CAD and CVD were recorded at the time of the first consultation and collected retrospectively from medical chart reviews. Cases and controls were divided into 2 different cohorts on the basis of BMI: BMI < 30 (Non-Obese), BMI $\geq 30$ (Obese). BMI was calculated as the body weight in kg divided by the square of the stature (height, in meters). Cases were also classified using Gleason grade at diagnosis as high-grade (Gleason score 8 - 10).

Differences in the distribution of continuous variables between study groups were described as median or media \pm standard deviation (SD) and assessed for statistical significance with Mann-Whitney Rank Sum Test or t-test. Differences in distributions for categorical variables were expressed as number of patients (frequencies and percentage) and evaluated using Chi-square testing of independence; however, when low cell counts were found, Fisher's exact testing was utilized. Odds ratios and 95\% CI's were calculated for the parameters in each group. A P value $<0.05$ was considered statistically significant.

\section{Results}

Cases and controls were age-matched (68 years vs 67 years, respectively, $\mathrm{p}=0.253$ ). Obesity was significantly

Table 1. Demographic and social characteristics of cases and controls.

\begin{tabular}{ccc}
\hline & Cases & Controls \\
\hline Patients (N) & 200 & 200 \\
Age (SD) & $68 \pm 5$ & $67 \pm 7$ \\
BMI (SD) & $27.32 \pm 3.31$ & $25.70 \pm 2.99$ \\
Smoking & $28 \%(56 / 200)$ & $29 \%(58 / 200)$ \\
Sedentary & $41 \%(83 / 200)$ & $36 \%(72 / 200)$ \\
\hline
\end{tabular}


associated (OR 2.34, p < 0.05) with aggressive PCa. Otherwise DMII was not related to aggressive PCa. After stratification by obesity, DMII individually was associated to aggressive PCa only in association with obesity (OR 4.25, p < 0.05) (Table 2, Figure 1). In non-obese men, no association was noted between DMII and highgrade $\mathrm{PCa}$.

CVD and CAD were significantly linked to PCa in all cases versus controls (OR 1.88, $\mathrm{p}<0.05$ ) (Figure 2).

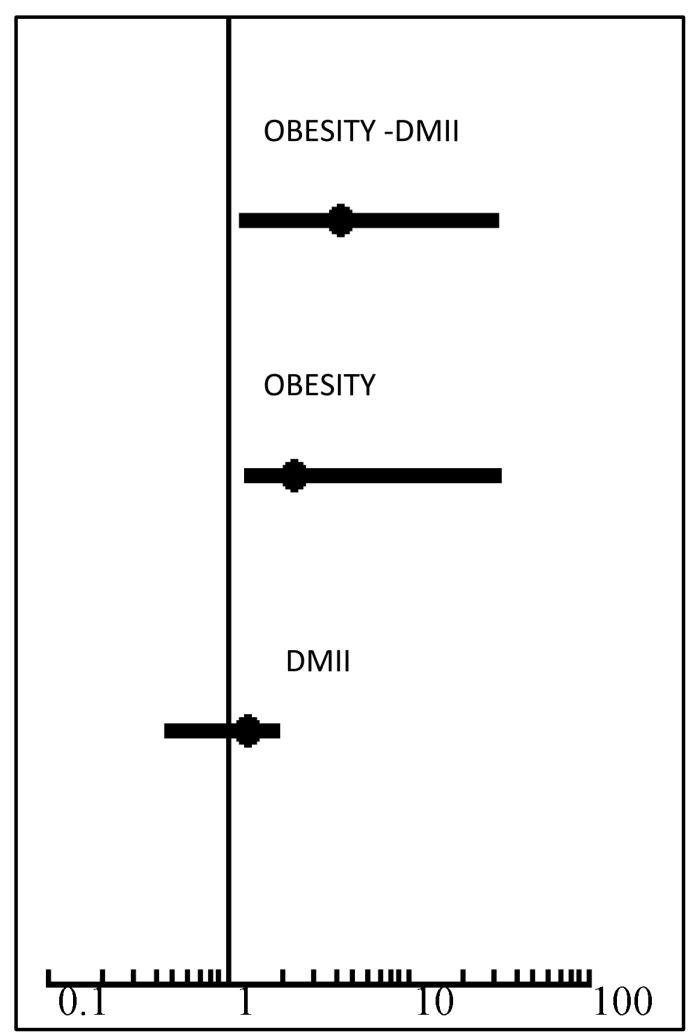

Figure 1. DMII and Obesity association with aggressive PCa. The figure shows a statistically significant association between obesity, DMII and aggressive PCa (OR 4.25, p < 0.05). No significant association was noted between DMII and high-grade PCa (OR $1.3, p=0.3)$. Obesity was significantly associated with aggressive PCa (OR 2.34, $\mathrm{p}<0.05$ ).

VASCULAR DISEASE AND PCa ASSOCIATION

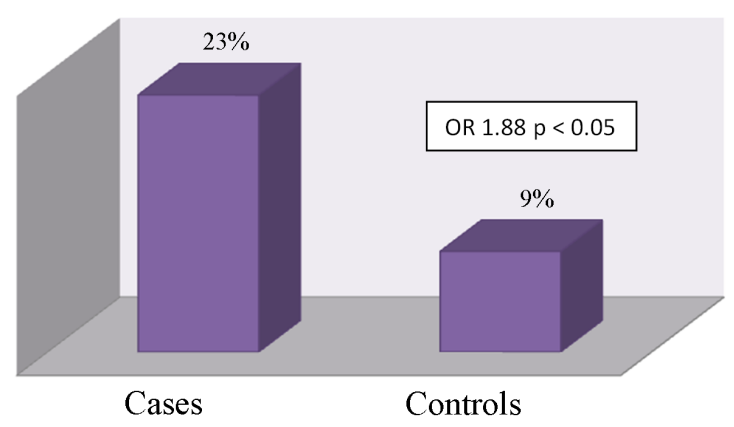

Figure 2. Vascular Disease and prostate cancer relationship. The figure shows a statistically significant association between vascular disease and PCa at initial diagnosis with an OR of 1.88 in cases with PCa. 
Table 2. DMII and obesity relationship in aggressive PCa.

\begin{tabular}{ccc}
\hline & Aggressive PCa & p \\
\hline DMII & OR 1.32 & 0.3 \\
Obesity & OR 2.34 & 0.04 \\
Obesity-DMII & OR 4.25 & 0.03 \\
\hline
\end{tabular}

\section{Discussion}

The aim of this study was to examine the association between Obesity, DMII and vascular disease (CVD and CAD) with PCa with further stratification of cases into subgroups according to body habitus and high-grade cancer.

In our study, similarly to recent literature, we found that obesity was significantly associated with increased high-grade PCa [1]-[3]. Particularly, men had a greater than 2-fold increased risk of high-grade disease, compared with non-obese men. The presence of a genetic link also between tumor cells and adipose tissue cells could create a favorable environment to PCa progression.

In our series DMII was associated with high-grade PCa only in obese men. Several plausible biologic mechanisms may explain this association. The link between obesity, DMII and PCa could be related to insulin resistance, hyperinsulinaemia, increased levels of IGF, steroid and peptide hormone imbalance and inflammation [19]. Particularly compensatory hyperinsulinaemia promotes PCa aggressiveness and progression [20]. Moreover, insulin secretory capacity was greater in obese patients with DMII than in non-obese patients with DMII [21]. Additionally, over time, DMII and obesity leads to decreased levels of serum testosterone, related to highgrade PCa [22]. Some reports suggest that low testosterone levels are associated with aggressive PCa, treatment failure after Radical Prostatectomy, high-grade disease (GS 8 - 10) and locally advanced pathologic stage (pT3 and pT4] [23] [24]. These findings suggest a possible role of steroid sex hormones in the contribution of obesity and DMII to the development of high-risk PCa.

Systemic inflammation also may contribute to PCa aggressiveness in obesity and DMII. DMII and obesity are pro inflammatory conditions and are associated with increased production of inflammatory cytokines such as Tumor Necrosis Factor (TNF- $\alpha$ ), Interleukin (IL) 6 and IL8 [25]. These cytokines stimulate the Nuclear Factor Kappa B (NF-kB) pathway, directly related to lymph node invasion and androgen-independent PCa progression [26] [27].

In our study a significant association was found between CVD, CAD and PCa at initial diagnosis. To date, only a few studies have explored the relationship between vascular injury and PCa, with conflicting results [28]-[32].

In REDUCE study vascular disease was associated with an increased risk of PCa diagnosis $(\mathrm{OR}=1.35)$ [32]. Our findings also are consistent with autopsy study of Stamatiou suggesting that men with PCa had greater advanced atheromatosis than subjects without PCa [30]. A study of 30,883 men with PCa hormone-naive, showed a statistical significantly increase in risk of ischemic heart disease for all men with PCa versus controls [33]. Similarly, Zoller et al. showed an increased risk of CAD during the first 6 months after diagnosis of PCa and after 10 years after diagnosis of cancer [34].

The present study has certain limitations. First, this research had a retrospective design and we had no information on certain important risk factors (family history of cardiovascular disease or hypertension and lipid status). Second, we lacked data on DMII duration or diabetic-medication use which may be a proxy for DMII severity. Finally, because this was a limited Caucasian sample of men, generalizing these findings to other racial groups may not be appropriate. Nonetheless, the present study is the first study aimed to investigate the association of Obesity, DMII and vascular damage in PCa hormone-naïve at initial diagnosis. If confirmed in other larger studies, our results suggested that vascular disease may be a novel PCa risk factor.

\section{Conclusion}

In our study, obesity, particularly in combination with DM, was significantly associated with aggressive PCa. Moreover, a significant relation was found between CVD, CAD and PCa hormone-naïve at initial diagnosis. The metabolic derangements may create a favorable environment to PCa progression and cause a permanent proin- 
flammatory state that predisposes to vascular disease and PCa. Further research should elucidate these relations in larger samples to confirm these associations and to stabilize future prevention strategies.

\section{References}

[1] Morote, J., Celma, A., Planas, J., Placer, J., Konstantinidis, C., Iztueta, I., de Torres, I.M., Oliván, M., Reventós, J. and Doll, A. (2013) Sedentarism and Overweight as Risk Factors for the Detection of Prostate Cancer and Its Aggressivenes. Actas Urol Esp.

[2] Parker, A.S., Thiel, D.D., Bergstralh, E., Carlson, R.E., Rangel, L.J., Joseph, R.W., Diehl, N. and Karnes, R.J. (2013) Obese Men Have More Advanced and More Aggressive Prostate Cancer at Time of Surgery than Non-Obese Men after Adjusting for Screening PSA Level and Age: Results from Two Independent Nested Case-Control Studies. Prostate Cancer Prostatic Disease, 16, 352-356. http://dx.doi.org/10.1038/pcan.2013.27

[3] Su, L.J., Arab, L., Steck, S.E., Fontham, E.T., Schroeder, J.C., Bensen, J.T. and Mohler, J.L. (2011) Obesity and Prostate Cancer Aggressiveness among African and Caucasian Americans in a Population-Based Study. Cancer Epidemiology Biomarkers Prevention, 20, 844-853. http://dx.doi.org/10.1158/1055-9965.EPI-10-0684

[4] Jayachandran, J., Aronson, W.J., Terris, M.K., Presti Jr., J.C., Amling, C.L., Kane, C.J. and Freedland, S.J. (2010) Diabetes and Outcomes after Radical Prostatectomy: Are Results Affected by Obesity and Race? Results from the Shared Equal-Access Regional Cancer Hospital Database. Cancer Epidemiology Biomarkers Prevention, 19, 9-17. http://dx.doi.org/10.1158/1055-9965.EPI-09-0777

[5] Gallina, A., Karakiewicz, P.I., Hutterer, G.C., Chun, F.K., Briganti, A., Walz, J., Antebi, E., Shariat, S.F., Suardi, N., Graefen, M., Erbersdobler, A., Salonia, A., Rigatti, P., Huland, H. and Montorsi, F. (2007) Obesity Does Not Predispose to More Aggressive Prostate Cancer Either at Biopsy or Radical Prostatectomy in European Men. International Journal of Cancer, 121, 791-795. http://dx.doi.org/10.1002/ijc.22730

[6] Wu, C., Aronson, W.J., Terris, M.K., Presti Jr., J.C., Kane, C.J., Amling, C.L. and Freedland, S.J. (2013) Diabetes Predicts Metastasis after Radical Prostatectomy in Obese Men: Results from the SEARCH Database. BJU International, 111, E310-E318. http://dx.doi.org/10.1111/j.1464-410X.2012.11687.x

[7] Margel, D., Urbach, D., Lipscombe, L.L., Bell, C.M., Kulkarni, G., Austin, P.C. and Fleshner, N. (2013) Association between Metformin Use and Risk of Prostate Cancer and Its Grade. Journal of National Cancer Institution, 105, 11231131.

[8] Hu, M., Xu, H., Bai, P., Jiang, H. and Ding, Q. (2014) Obesity Has Multifaceted Impact on Biochemical Recurrence of Prostate Cancer: A Dose-Response Meta-Analysis of 36,927 Patients. Medical Oncology, 31, 829. http://dx.doi.org/10.1007/s12032-013-0829-8

[9] Gallina, A., Karakiewicz, P.I., Hutterer, G.C., Chun, F.K., Briganti, A., Walz, J., Antebi, E., Shariat, S.F., Suardi, N., Graefen, M., Erbersdobler, A., Salonia, A., Rigatti, P., Huland, H. and Montorsi, F. (2007) Obesity Does Not Predispose to More Aggressive Prostate Cancer Either at Biopsy or Radical Prostatectomy in European Men. International Journal of Cancer, 121, 791-795. http://dx.doi.org/10.1002/ijc.22730

[10] Turner, E.L., Lane, J.A., Donovan, J.L., Davis, M.J., Metcalfe, C., Neal, D.E., Hamdy, F.C. and Martin, R.M. (2011) Association of Diabetes Mellitus with Prostate Cancer: Nested Case-Control Study (Prostate Testing for Cancer and Treatment Study). International Journal of Cancer, 128, 440-446. http://dx.doi.org/10.1002/ijc.25360

[11] Satariano, W.A., Ragland, K.E. and Van Den Eeden, S.K. (1998) Cause of Death in Men Diagnosed with Prostate Carcinoma. Cancer, 83, 1180-1188. http://dx.doi.org/10.1002/(SICI)1097-0142(19980915)83:6<1180::AID-CNCR18>3.0.CO;2-1

[12] Fouad, M.N., Mayo, C.P., Funkhouser, E.M., Hall, H.I., Urban, D.A. and Kiefe, C.I. (2004) Comorbidity Independently Predicted Death in Older Prostate Cancer Patients, More of Whom Died with than from Their Disease. Journal of Clinical Epidemiology, 57, 721-729. http://dx.doi.org/10.1016/j.jclinepi.2003.11.009

[13] Groome, P.A., Rohland, S.L., Siemens, D.R., Brundage, M.D., Heaton, J. and Mackillop, W.J. (2011) Assessing the Impact of Comorbid Illnesses on Death within 10 Years in Prostate Cancer Treatment Candidates. Cancer, 117, 39433952. http://dx.doi.org/10.1002/cncr.25984

[14] Omalu, B.I., Hammers, J.L., Parwani, A.V., Balani, J., Shakir, A. and Ness, R.B. (2013) Niger Is There an Association between Coronary Atherosclerosis and Carcinoma of the Prostate in Men Aged 50 Years and Older? An Autopsy and Coroner Based Post-Mortem Study. Journal of Clinical Practice, 16, 45-48.

[15] Dreyer, L. and Olsen, J.H. (1999) Risk for Non-Smoking-Related Cancer in Atherosclerotic Patients. Cancer Epidemiological Biomarkers Prevention, 8, 915-918.

[16] Stamatiou, K.N., Alevizos, A.G., Mihas, K., Mariolis, A.D., Michalodimitrakis, E. and Sofras, F. (2007) Associations between Coronary Heart Disease, Obesity and Histological Prostate Cancer. International Urology and Nephrology, 39, 197-201. 
http://dx.doi.org/10.1007/s11255-006-9010-z

[17] Heron, M., Hoyert, D.L., Murphy, S.L., Xu, J., Kochanek, K.D. and Tejada-Vera, B. (2009) Deaths: Final Data for 2006. National Vital Statistics Reports, 57, 1-134.

[18] Thomas, J.A., Gerber, L., Bañez, L.L., Moreira, D.M., Rittmaster, R.S., Andriole, G.L. and Freedland, S.J. (2012) Prostate Cancer Risk in Men with Baseline History of Coronary Artery Disease: Results from the REDUCE Study. Cancer Epidemiol Biomarkers Prevention, 21, 576-581. http://dx.doi.org/10.1158/1055-9965.EPI-11-1017

[19] Cohen, D.H. and LeRoith, D. (2012) Obesity, Type 2 Diabetes, and Cancer: The Insulin and IGF Connection. Endocrine-Related Cancer, 19, F27-F45. http://dx.doi.org/10.1530/ERC-11-0374

[20] Ma, J., Li, H., Giovannucci, E., et al. (2008) Prediagnostic Body-Mass Index, Plasma C-Peptide Concentration, and Prostate Cancer-Specific Mortality in Men with Prostate Cancer: A Long-Term Survival Analysis. Lancet Oncology, 9, 1039-1047. http://dx.doi.org/10.1016/S1470-2045(08)70235-3

[21] Duman, B.S., Turkoglu, C., Gunay, D., Cagatay, P., Demiroglu, C. and Buyukdevrim, A.S. (2003) The Interrelationship between Insulin Secretion and Action in Type 2 Diabetes Mellitus with Different Degrees of Obesity: Evidence Supporting Central Obesity. Diabetes, Nutrition \& Metabolism, 16, 243-250.

[22] Moreira, D.M., Anderson, T., Gerber, L., Thomas, J.A., Bañez, L.L., McKeever, M.G., Hoyo, C., Grant, D., Jayachandran, J. and Freedland, S.J. (2011) The Association of Diabetes Mellitus and High-Grade Prostate Cancer in a Multiethnic Biopsy Series. Cancer Causes \& Control, 22, 977-983. http://dx.doi.org/10.1007/s10552-011-9770-3

[23] Xylinas, E., Ploussard, G., Durand, X., et al. (2011) Low Pretreatment Total Testosterone $(<3$ ng/mL) Predicts Extraprostatic Disease in Prostatectomy Specimens from Patients with Preoperative Localized Prostate Cancer. BJU International, 107, 1400-1403. http://dx.doi.org/10.1111/j.1464-410X.2010.09816.X

[24] Yamamoto, S., Yonese, J., Kawakami, S., Ohkubo, Y., Tatokoro, M., Komai, Y., Takeshita, H., Ishikawa, Y. and Fukui, I. (2007) Preoperative Serum Testosterone Level as an Independent Predictor of Treatment Failure Following Radical Prostatectomy. European Urology, 52, 696-701. http://dx.doi.org/10.1016/j.eururo.2007.03.052

[25] Eltzschig, H.K. and Carmeliet, P. (2011) Hypoxia and Inflammation. New England Journal of Medicine, 364, $656-665$.

[26] Jin, R.J., Lho, Y., Connelly, L., Wang, Y., Yu, X., Saint Jean, L., Case, T.C., Ellwood-Yen, K., Sawyers, C.L., Bhowmick, N.A., Blackwell, T.S., Yull, F.E. and Matusik, R.J. (2008) The Nuclear Factor- $\kappa B$ Pathway Controls the Progression of Prostate Cancer to Androgen-Independent Growth. Cancer Research, 68, 6762-6769. http://dx.doi.org/10.1158/0008-5472.CAN-08-0107

[27] Gorbachinsky, I., Akpinar, H. and Assimos, D.G. (2010) Metabolic Syndrome and Urologic Diseases. Reviews in Urology, 12, e157-e180.

[28] Omalu, B.I., Hammers, J.L., Parwani, A.V., Balani, J., Shakir, A. and Ness, R.B. (2013) Is there an Association Between Coronary Atherosclerosis and Carcinoma of the Prostate in Men Aged 50 Years and Older? An Autopsy and Coroner Based Post-Mortem Study. Nigerian Journal of Clinical Practice, 16, 45-48.

[29] Dreyer, L. and Olsen, J.H. (1999) Risk for Non-Smoking-Related Cancer in Atherosclerotic Patients. Cancer Epidemiology Biomarkers \& Prevention, 8, 915-918.

[30] Stamatiou, K.N., Alevizos, A.G., Mihas, K., Mariolis, A.D., Michalodimitrakis, E. and Sofras, F. (2007) Associations between Coronary Heart Disease, Obesity and Histological Prostate Cancer. International Urology and Nephrology, 39, 197-201. http://dx.doi.org/10.1007/s11255-006-9010-z

[31] Heron, M., Hoyert, D.L., Murphy, S.L., Xu, J., Kochanek, K.D. and Tejada-Vera, B. (2009) Deaths: Final Data for 2006. National Vital Statistics Reports, 57, 1-134.

[32] Thomas, J.A., Gerber, L., Bañez, L.L., Moreira, D.M., Rittmaster, R.S., Andriole, G.L. and Freedland, S.J. (2012) Prostate Cancer Risk in Men with Baseline History of Coronary Artery Disease: Results from the REDUCE Study. Cancer Epidemiology Biomarkers \& Prevention, 21, 576-581. http://dx.doi.org/10.1158/1055-9965.EPI-11-1017

[33] Robinson, D., Garmo, H., Lindahl, B., Van Hemelrijck, M., Adolfsson, J., Bratt, O., Holmberg, L. and Stattin, P. (2012) Ischemic Heart Disease and Stroke before and during Endocrine Treatment for Prostate Cancer in PCBaSe Sweden. International Journal of Cancer, 130, 478-487. http://dx.doi.org/10.1002/ijc.26022

[34] Zöller, B., Ji, J., Sundquist, J. and Sundquist, K. (2012) Risk of Coronary Heart Disease in Patients with Cancer: A Nationwide Follow-Up Study from Sweden. European Journal of Cancer, 48, 121-128.

http://dx.doi.org/10.1016/j.ejca.2011.09.015 